Скорее всего, вашингтонские аналитики в преддверии прогнозируемых ими кадровых перестановок в кубинском руководстве хотят разыграть сюжет в духе «перестройки» в СССР с последующим мягким демонтажем режима. Это, по сути дела, еще один из векторов «переформатирования» Латинской Америки под американские интересы, чем США начали плотно заниматься в последнее время.

\title{
Литература
}

1. Respiro en Venezuela (editorial) // [Электронный ресурс]. URL: http://elpais.com/ elpais/2015/06/24/opinion/1435167153_454556.html

2. См.: Орлов А.А. Терроризм в Испании: международный аспект // Обозреватель Observer. 2009. № 11 (238). - С. 65-73; Орлов А.А. Проблема терроризма в Испании на современном этапе // Обозреватель - Observer. 2009. № 12 (239). - С. 55-61; Орлов А.А. Историческая основа терроризма в Испании // Обозреватель - Observer. - 2009. № 10 (237). - С. 80-87; Орлов A.A. Проблема терроризма в Испании. ЭТА - «ударный отряд» баскского национализма. - М.: Русская панорама, 2009; Хенкин С.М., Самсонкина Е.С. Баскский конфликт. - М.: МГИМО-Университет МИД России, 2011.

3. Окунева Л.С. Бразилия: особенности демократического проекта: Страницы новейшей политической истории латиноамериканского гиганта (1960-е гг. - 2006 г.). М.: МГИМОУниверситет, 2008. - С. 30.

4. Nelson Barbosa: "Brasil volverá a crecer en el último trimestre del año" // URL: http:// internacional.elpais.com/internacional/2015/06/24/actualidad/1435098014_193614.html 5. Argentina, un país sin datos oficiales // URL: http://internacional.elpais.com/internacional/ 2015/06/24/actualidad/1435099251_541614.html

6. Argentina irá a segunda vuelta tras la mínima victoria del oficialista Scioli// URL: http://internacional.elpais.com/internacional/2015/10/25/argentina/1445811339_529911.html

\section{А.Н. Рылова}

\section{Саморегулирование журналистики в Испании}

Саморегулирование жмурналистики - это меры, добровольно предпринимаемые профессиональным сообществом журналистов, для обеспечения соблюдения определенных принципов в процессе информирования общественности, сохранения независимости СМИ и доверия к ним населения. Институт саморегулирования журналистики в Испании сложился значительно позже, чем в других западных странах. Причина этого кроется в исторических особенностях взаимодействия испанской журналистики и государства: в Испании долгое время существовали административный контроль за СМИ и ущемление свободы слова. Из-за этого первые попытки учредить органы саморегулирования после падения диктатуры Ф. Франко вызывали опасения возврата к временам цензуры. Однако отставание в вопросе саморегулирования СМИ впоследствии позволило Испании воспользоваться опытом других стран. В настоящее время саморегулирование журналистики в Испании находится на одном уровне с другими странами Запада. Институт успешно функционирует и способствует укреплению авторитета испанских СМИ.

Ключевые слова: Испания, саморегулирование журналистики, независимость СМИ, цензура, авторитет СМИ. 


\section{A. Rilova \\ SELF-REGULATION OF JOURNALISM IN SPAIN}

Self-regulation of journalism resides in voluntary measures taken by the professional community of journalists to guarantee the observation of certain rules and principles in the process of providing information to public, maintain independence and credibility of media. The institution of self-regulation of Spanish journalism emerged later than in other Western countries due to the history of interaction between the State and media: for a long time Spanish media were under State control and freedom of expression was constantly defied. That is why first attempts to establish bodies for self-regulation of journalism in the post-Franco Spain evoked fears of a return to censorship. However, the time lag concerning media selfregulation allowed Spain to use other countries' experience. Nowadays, the degree of self-regulation of journalism in Spain is similar to that of the Western countries. The institution of self-regulation operates successfully and facilitates Spanish media authority.

Key words: Spain, self-regulation of journalism, independence of media, censorship, media authority.

Саморегулирование журналистики - это меры, предпринимаемые профессиональным сообществом, которые представляют собой добровольное соблюдение определенных принципов и норм в процессе информирования общественности. Саморегулирование СМИ улучшает качество их работы, повышает степень доверия к ним аудитории, а также помогает сохранять независимость в условиях давления со стороны государства и бизнеса.

Импульсом к формированию института саморегулирования журналистики изначально была внешняя критика отрасли. Она была вызвана коммерциализацией журналистики и ориентацией ее на массового читателя, что неизбежно отражалось на ее качестве и привело к потере доверия общественности. Другим важным фактором стали попытки государства повлиять на независимость СМИ при помощи различных рычагов, в том числе экономических. Так, стали появляться своды внутренних норм, которые должны были защитить журналистику от саморазрушения и внешнего давления. Первые профессиональные кодексы журналистов стали появляться во второй половине XIX в. Позднее стали формироваться специальные органы саморегулирования СМИ в разных странах. Старейший орган саморегулирования журналистики - Шведский совет по прессе, или Суд чести, созданный еще в 1916 г.

Органы саморегулирования журналистики появились в Испании значительно позже, чем в других странах Запада. Это объясняется историческими причинами развития испанской журналистики. Однако это отставание позволило Испании воспользоваться успешным опытом других стран, чтобы в краткие сроки наверстать упущенное. Ориентиром для организации саморегулирования СМИ в Испании служили зарубежные профессиональноэтические кодексы и органы саморегулирования. Важную роль сыграла резолюция Парламентской Ассамблеи Совета Европы 1003 (1993 г.) «О журналистской этике», одним из составителей которой был испанец Мануэль Нуньес Энкабо. В ней были провозглашены этические принципы, которыми должны руководствоваться журналисты по всей Европе.

В настоящее время саморегулирование журналистики в Испании, несмотря на свое довольно позднее появление, успешно функционирует и развивается, что способствует укреплению авторитета испанских СМИ как внутри страны, так и за рубежом. Испания сумела преодолеть свое отставание в этой сфере и сейчас находится на одном уровне с другими странами Запада.

Федерация журналистских ассоциаций Испании (FAPE) была основана в мае 1922 г. в Сантандере.Этопервая в своем роде профессиональная организация журналистов Испании. В настоящее время в нее входят 48 местных журналистских ассоциаций, еще 16 ассоциаций с ней сотрудничают. Всего в Федерации состоит 21 тыс. журналистов. Официальный статус организации установлен в соответствии с законом «О профессиональных ассоциациях» 1977 г. В своей деятельности FAPE руководствуется Уставом, принятым на Генеральной Ассамблее в Севилье в 2008 г. FАРЕ издает собственный журнал «Журналисты» (Periodistas). 
C 1993 г. в рамках FAPE начался процесс создания специального органа, отвечающего за саморегулирование отрасли и соблюдение профессионально-этических норм испанскими журналистами. Тогда был принят Деонтологический кодекс FAPE, закрепивший основные профессиональные принципы журналистики Испании. Но лишь к 2004 г. был учрежден Деонтологический совет, позднее переименованный в Комиссию по арбитражу, жалобам и профессиональной этике.

Комиссия по арбитражу, жалобам и профессиональной этике - это орган внутреннего деонтологического самоконтроля журналистской профессии. Комиссия обладает моральным авторитетом в отношении ассоциированных с FAPE журналистских организаций. Ее основная задача - гарантировать соблюдение Деонтологического кодекса Федерации.

Между тем в Испании, еще до создания национального органа саморегулирования журналистики, действовал региональный Совет по прессе (Consell de Informació), основанный в Каталонии в 1996 г. Такжедеятельность отдельных средств массовой информации Испании регулировалась собственными внутренними уставами редакций и сводами норм.

Тот факт, что институт саморегулирования журналистики в Испании долгое время не получал развития можно объяснить историческими причинами. Большую часть ХХ в. свобода слова в Испании подавлялась или жестко контролировалась. Свобода прессы в Испании была провозглашена еще в Конституции 1876 г., однако на практике она не была реализована, так как в другой статье той же Конституции говорилось, что осуществление определенных конституционных прав может быть приостановлено, «если того требует безопасность государства» [1]. В результате правительство прибегало к этой оговорке почти на ежедневной основе. В 1923 г., при короле Альфонсо ХІІІ, ввиду полной недееспособности государственного аппарата, в Испании была установлена военная диктатура генерала Мигеля Примо де Риверы. Одновременно была введена предварительная цензура печати, просуществовавшая до 1930 г., когда на фоне общественного недовольства Примо де Ривера был вынужден подать в отставку, и диктатура пала. В период Второй Испанской Республики (1931-1939 гг.) положение свободы слова было противоречивым. С одной стороны, правительство республиканцев приняло декреты, которые укрепляли свободу прессы и объявляли амнистию по преступлениям, связанным с цензурой времен военной диктатуры. С другой стороны, был одобрен закон «О защите Республики», запрещавший публикацию новостей, которые могли нанести вред общественному порядку и социальному миру.

Носамый жесткий контроль запрессой существовал вовремядиктатуры Франсиско Франко (1939-1975 гг.). Первые десятилетия франкистской диктатуры действовал Закон о прессе, принятый еще до окончания гражданской войны в 1938 г. Согласно ему, вновь вводилась предварительная цензура, а также создавались структуры: Национальный отдел по прессе и пропаганде, Национальное радио Испании и информационное агентство Еfe, которые впоследствии сыграли большую роль в осуществлении правительственной пропаганды. Фактически пресса была подчинена государству и должна была выполнять политические задачи и распространять национал-синдикалистские идеи [2]. Существовала особая система инструкций для периодики, в соответствии с которой печатные издания были обязаны публиковать на своих страницах официальную информацию, передаваемую «сверху». За назначение и смещение главных редакторов газет отвечал сам министр внутренних дел. Правительственному контролю подвергались и сами журналисты. Монополия на журналистское образование в течение почти двадцати лет принадлежала Официальной школе журналистов, учрежденной в 1941 г. Обязательным условиям поступления туда было членство во франкистской партии «Испанская фаланга» и ХОНС, которую возглавлял сам Франко. Тем самым обеспечивалась верность журналистов партии и правительственному курсу. Только в 1960-е гг. появились три новых журналистских учебных заведения, хотя и они были учреждены католическими организациями, верными франкизму.

Начиная с 1950-х гг. режим диктатуры стал постепенно смягчаться, страна стала отказываться от политики автаркии и преодолевала международную изоляцию. 
Меняющаяся ситуация потребовала принятия нового, более мягкого закона о прессе, который был одобрен в 1966 г. Закон 1966 г. отменил предварительную цензуру за исключением периодов чрезвычайного или военного положения, вместо нее была введена так называемая «добровольная консультация». Была упразднена система, но обязательство бесплатно публиковать «информацию, представляющую общий интерес», сохранялось. Также разрешалось создание негосударственных журналистских организаций, однако государство оставляло за собой право отказать им в регистрации, проводить инспекции финансовой отчетности и проверять акционеров. Были распространены судебные расследования по поводу публикации тех или иных материалов. Всего с 1966 по 1975 гг. было возбуждено 1270 уголовных дел против газет и журналов [3]. Опасаясь проблем с законом, многие редакции и отдельные журналисты прибегали к самоцензуре. Кроме того, вся информация, поступающая из-за рубежа, в обязательном порядке проходила через правительственное информационное агентство Efe, где ее тщательно «фильтровали». Таким образом, несмотря на объявленный «реформистский» характер нового Закона о прессе и некоторые послабления, свобода слова и выражения в Испании продолжала оставаться под строгим контролем франкистского аппарата. Такая ситуация продолжалась вплоть до смерти Франко и окончания периода диктатуры в 1975 г. И только в Ст. 20 Конституции Испании 1978 г. были признаны и закреплены права испанцев на «свободное выражение и распространение взглядов, идей и мнений устно, письменно или иными средствами» и «свободную передачу и получение достоверной информации посредством любых средств распространения» [4], и на этот раз они существовали не только на бумаге.

Когда после стольких лет несвободы и жесткого контроля над средствами массовой информации стали предприниматься первые попытки создать орган самоконтроля журналистики, и редакторы, и журналисты относились к ним либо с опаской, либо с насмешкой, так как видели в них угрозу возврата к временам цензуры и вмешательства в деятельность СМИ, характерных для периода диктатуры. Первое время сложно было забыть о перипетиях прошлого и понять, что в демократическом обществе, переход к которому Испания совершила мирно и в краткие сроки, саморегуляция преследует иные цели и благотворна для поддержания независимости СМИ. Только к середине 2000-х гг. испанское медийное сообщество наконец «созрело» для создания независимого органа саморегуляции журналистики.

Восуществлениисвоейдеятельности Комиссияпоарбитражу, жалобамипрофессиональной этике ориентируется на нормы Деонтологического кодекса FAPE, а также на собственный Регламент, принятый 29 ноября 2013 г.

В Регламенте закреплены следующие функции Комиссии:

- Информировать общественность и высказывать мнение по вопросам, связанным с соблюдением профессиональной этики журналистами.

- Рассматривать и разрешать дела, инициированные в связи с возможным несоблюдением Деонтологического кодекса. Комиссия рассматривает жалобы как по собственной инициативе, так и по заявлению Федерации или любого гражданина Испании.

- Осуществлять арбитражное разбирательство и выступать посредником в спорах, связанных с профессионально-этическими нормами [5].

Также в Регламенте Комиссии подробно описана процедура подачи и рассмотрения жалоб. В общем виде она такова: любое физическое или юридическое лицо, пострадавшее от журналистской деятельности, которая, по их мнению, нарушает нормы Деонтологического кодекса, имеет право обратиться в Комиссию с просьбой начать разбирательство по данному делу; жалоба должна быть подана в течение двух месяцев с момента публикации материала, нарушающего профессиональные нормы журналистики. Сам процесс рассмотрения жалобы является гибким и зависит от конкретной ситуации. Обе стороны - пострадавшая и обвиняемая - имеют право быть выслушанными во время рассмотрения жалобы. Стороны могут участвовать в разбирательстве лично, или их интересы могут защищать их представители. Предварительные решения Комиссии могут быть отправлены на повторное 
рассмотрение, окончательные решения обжалованию не подлежат, однако это не исключает возможности обращения в другие инстанции, в том числе судебные. В окончательном решении Комиссии констатируются нарушенные профессиональные нормы, а также излагаются меры, которые Комиссия рекомендует предпринять, чтобы компенсировать причиненный ущерб. Это может быть: публикация решения Комиссии в СМИ, нарушившем Деонтологический кодекс; публикация опровержения/исправленной информации; публикация извинений в адрес пострадавшей стороны и другие аналогичные меры.

Деонтологический кодекс FAPE закрепляет следующие основные принципы журналистской профессии: обязательное соблюдение норм Кодекса, уважение правды, свобода расследования и честного распространения информации, свобода комментирования и критики, уважение частной жизни граждан (вмешательство оправдано, только если речь идет о защите интересов общества; ограничения на вмешательство тщательно соблюдаются, если речь идет о людях, помещенных в медицинские учреждения); соблюдение презумпции невиновности, пока судом не будет доказано обратное (с особой строгостью исполняется, когда речь идет об интересах несовершеннолетних); недопустимость дискриминации на каких-либо основаниях. Также в Кодексе излагаются права и обязанности журналистов, принципы действий для получения достоверной информации законным способом. Многие нормы Деонтологического кодекса FАРЕ совпадают с Кодексом профессиональной этики российского журналиста 1994 г., а также сводами профессионально-этических норм других стран.

Существует еще целый ряд документов, содержащих этические нормы, которые также учитываются Комиссией по арбитражу, жалобам и профессиональной этике. К ним относятся: Кодекс информационного освещения случаев гендерного насилия (Código para el Tratamiento Informativo de la Violencia de Género [6]), принятый администрацией автономии Кастилия и Леон; Кодекс поведения членов Ассоциации журналистов, пишущих об экономической информации (APIE); Деонтологический кодекс Совета по прессе Каталонии, резолюция Парламентской Ассамблеи Совета Европы «О журналистской этике», Международная декларация принципов поведения журналистов 1954 г., Деонтологический кодекс профсоюза журналистов Мадрида, редакционные уставы СМИ (газеты El Mundo, El País, La Vanguardia, ИA Efe), руководства по стилю (manuales de estilo).

Комиссия по арбитражу, жалобам и профессиональной этике FAPE - не единственный институт саморегулирования испанской журналистики. Существует также институт омбудсмена или, как его называют в Испании, «защитника читателя» (defensor del lector).

«Омбудсмен» в переводе со шведского означает «представитель». Это гражданское, а иногда должностное лицо, которое представляет интересы определенных групп населения в их взаимодействии с органами государственной власти. Применительно к прессе данный термин был впервые использован в США в 1967 г., когда газета «Курьер-Джорнал» (Луисвилль, штат Кентукки) поручила бывшему главе отдела местной информации заниматься взаимоотношениями между читателями и журналистами [7]. Позднее этому примеру последовали другие страны.

В отличие от советов по прессе, чье влияние распространяется на все журналистское сообщество страны, омбудсмены работают в конкретных средствах массовой информации. В их функции входит поддержание связи между редакцией и аудиторией, ответы на комментарии и жалобы, урегулирование возникающих разногласий.

В Испании первый омбудсмен появился раньше, чем был создан специальный орган саморегулирования журналистики. Пионером стала газета El País, где должность защитника читателя была учреждена в 1986 г. В 1993 г. омбудсмен появился в La Vanguardia, в 2001 г. - в La Voz de Galicia, в 2004 г. - в El Correo Gallego. Что касается телевидения, то первым «защитником телезрителя» обзавелся канал RTVA в 1995 г., а государственная телерадиокомпания Испании - RTVE - только в 2006 г. [8].

Появление института омбудсмена СМИ в Испании стало ответом как на внешние, так внутренние вызовы, с которыми столкнулась журналистика. С одной стороны, испанские СМИ, особенно печатные, часто подвергались и подвергаются критике со стороны 
общественности за необъективность и поддержку одной из двух основных политических партий Испании - ИСРП и Народной партии. С другой стороны, испанские СМИ часто вызывают критику своих коллег по цеху, которые, борясь за аудиторию, стараются очернить конкурента. Таким образом, в определенный момент появление такой фигуры, как омбудсмен, стало необходимым требованием для сохранения доверия к журналистской профессии. Главная цель омбудсмена в 1980-х гг. заключалась в том, чтобы донести до общественности, что признание собственных ошибок и исправление их - в интересах самих СМИ. Учитывая, что журналистика - это прежде всего служение на благо общества, журналист всегда должен быть готов воспринимать общественную критику.

Рассмотрим подробнее, как работает защитник читателя в Испании на примере газеты El País.

Первый номер газеты El País появился на свет 4 мая 1976 г., всего через несколько месяцев после смерти Ф. Франко. Она стала первым демократическим изданием в постфранкистской Испании. Также она стала первой газетой Испании, закрепившей внутренние нормы контроля качества журналистики. В 1980 г. был принят редакционный устав газеты, а в 1986 г. появилась должность защитника читателей El País. Газета опередила другие издания и в составлении собственного Руководства по стилю, которое с течением времени претерпело 22 переиздания (последнее - в мае 2014 г.). В Руководстве по стилю перечислены этические принципы, соблюдаемые редакцией, один из которых гласит: «Издание должно первым указывать на ошибки, допущенные на собственных страницах, и исправлять их как можно скорее и без утайки» [9]. Большую роль в выполнении этого принципа играет защитник читателя. Омбудсмен El País отвечает за соблюдение прав читателей, отвечает на их просьбы, жалобы, замечания и предложения, следит за тем, чтобы информационное освещение событий в газете соответствовало этическим и профессиональным нормам журналистики. Он также помогает поддерживать связь между авторами и их читателями. Вмешательство омбудсмена возможно по просьбе читателя или по собственной инициативе. С сентября 2014 г. должность защитника читателя в газете El País занимает Лола Галан. После того, как омбудсмен рассмотрит и расследует какой-либо вопрос или обращение, в самой газете и в блоге омбудсмена на официальном сайте El País публикуется статья, посвященная данной проблеме.

Подводя итоги исследования, подчеркнем, что становление института саморегулирования СМИ в Испании началось значительно позже, чем в других западных странах. Из-за более позднего перехода к демократии, без которой немыслима свобода слова, а также из-за сложной истории взаимоотношений журналистики и государства, продолжительного правительственного контроля за деятельностью СМИ, в первые годы после падения франкистской диктатуры все идеи о создании органов саморегулирования вызывали опасения возврата к временам цензуры. Тем не менее, когда Испания оказалась готова к созданию собственных механизмов саморегулирования журналистики, в ее распоряжении оказался богатый опыт, накопленный другими странами, что позволило ей быстро и успешно восполнить существующие пробелы.

В Испании саморегулирование журналистики осуществляется как на общенациональном, так и на региональном уровнях. За соблюдение профессионально-этических норм всем журналистским сообществом отвечает Комиссия по арбитражу, жалобам и профессиональной этике Федерации журналистских ассоциаций Испании, за уважение этических норм в отдельных СМИ - собственные пресс-омбудсмены в редакциях. Все граждане Испании имеют право обратиться в данные органы с жалобами на нарушение профессиональной этики, либо с замечаниями и предложениями по работе СМИ, и ни одно обращение не остается без внимания. Это позволяет избегать ошибок или сократить их количество, улучшить работу СМИ, повысить степень доверия аудитории.

Существование органов саморегулирования журналистики в современной Испании имеет большое значение. К сожалению, многие средства массовой информации Испании имеют оттенок «партийной принадлежности», что может повлиять на объективность передаваемой ими информации. В этих условиях усиление внутреннего контроля и строгое соблюдение 
профессионально-этических норм могут сыграть ключевую роль в обеспечении гарантий конституционно закрепленного права на свободную передачу и получение достоверной информации.

\section{Литература}

1. Алексеева T.А. История испанской конституции. - М.: Проспект, 2011, с. 233.

2. Mesa R.Y. La complicada evolución de la libertad de prensa en España durante el siglo XX. Apuntes para su estudio. Espéculo. Revista de estudios literarios. Universidad Complutense de Madrid, 2005.

3. Mesa R.Y. Op. cit.

4. Конституция Испании на русском языке. Перевод П. Романа. Посольство Королевства Испании в Российской Федерации, 1995.

5. [Электронный ресурс]. URL: http://www.comisiondequejas.com/Reglamento/Reglamento. htm

6. [Электронный ресурс]. URL:

http://www.comisiondequejas.com/Otras_Normas/Codigos/Relacion/CODIGO_MEDIOS_ COMUNICACI\%D3N.pdf

7. Харасти М. Путеводитель по саморегулированию СМИ. Бюро Представителя ОБСЕ по вопросам свободы СМИ. - Вена, 2008, с. 78.

8. Maciá Barber C. A Press Ombudsman Model for Improvement of Journalistic Practices in Spain. Communication \& Society 19(1), 2006. P. 47-66.

9. Libro de Estilo de El País. [Электронный pecypc]. URL: http://blogs.elpais.com/defensordel-lector/doc/principios_eticos.pdf

\section{С.И. Чернявский}

\section{Россия и Испания в годы Великой войны [1914-1918 гг.]}

Статья посвящена сотрудничеству между Россией и Испанией по оказанию помощи депортированным русским подданным и военнопленным в 1914-1918г2.

Ключевые слова: депортация гражданских лиц, защита прав воен-нопленных.

\section{S. Cherniavsky}

RUSSIA AND SPAIN DURING THE GREAT WAR (1914-1918)

The article is devoted to cooperation between Russia and Spain to assist deported Russian citizen and prisoners of war in 1914-1918.

Key words: the deportation of civilians, protection of the rights of prison-ers of war.

В европейской политике Российской империи Испании никогда не принадлежало центральное место. В начале прошлого столетия отношения между нашими странами носили в целом вялотекущий характер. Это отражалось и на внутренней жизни посольств - небольшие здания в Мадриде и Петербурге, лишенные какой-либо помпезности, ограниченный персонал: посол и 2-3 сотрудника, отсутствие консульских точек. Ну и, наконец, весьма скромные дипломатические приемы, связанные с ограниченным финансированием. 